\title{
From pilots to regional programs: Expanding contraceptive choice and improving quality of care in Zambia's Copperbelt
}

Jill Keesbury

Population Council

Follow this and additional works at: https://knowledgecommons.popcouncil.org/departments_sbsr-rh

Part of the Demography, Population, and Ecology Commons, Health Services Research Commons, and the International Public Health Commons How does access to this work benefit you? Let us know!

\section{Recommended Citation}

Keesbury, Jill. 2007. "From pilots to regional programs: Expanding contraceptive choice and improving quality of care in Zambia's Copperbelt," FRONTIERS Final Report. Nairobi: Population Council. 


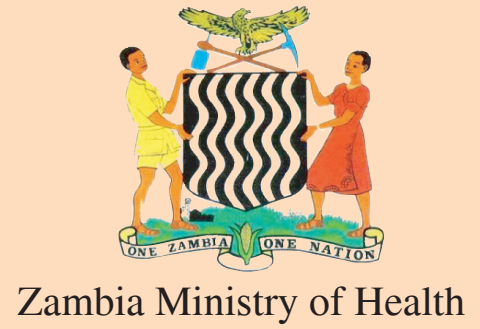

From Pilots to Regional Programs: Expanding Contraceptive Choice and Improving Quality of Care in Zambia's Copperbelt

Final Project Report

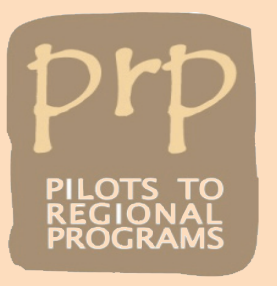




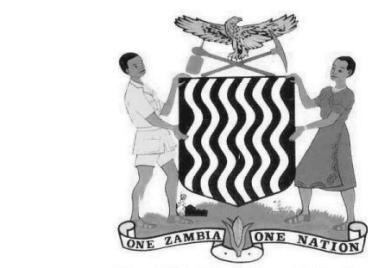

Zambia Ministry of Health

From Pilots to Regional Programs: Expanding Contraceptive

Choice and Improving Quality of Care in Zambia's Copperbelt

\section{Final Project Report}

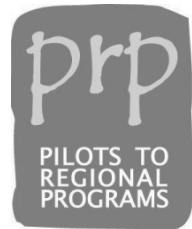

July 2007 


\section{TABLE OF CONTENTS}

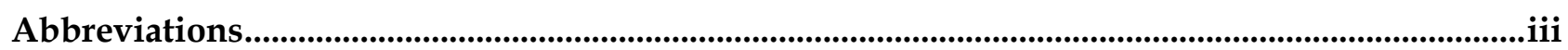

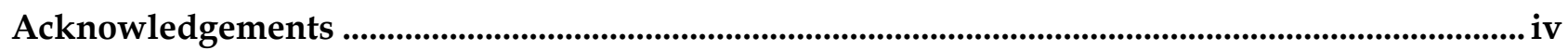

Executive Summary …............................................................................................................................................. v

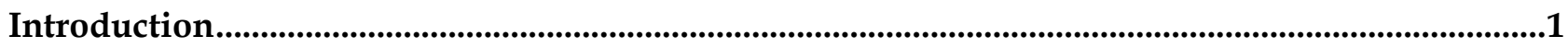

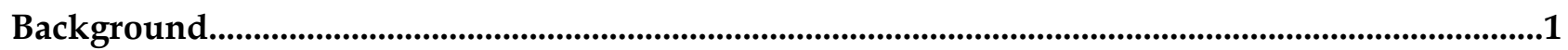

The Conceptual Framework for Scaling Up...................................................................................................3

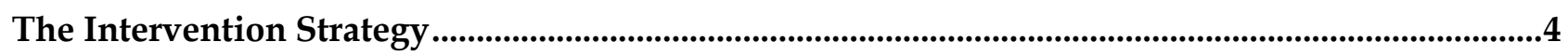

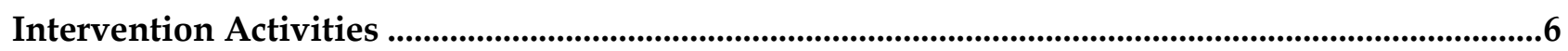

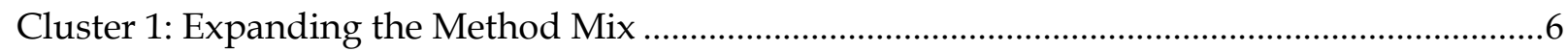

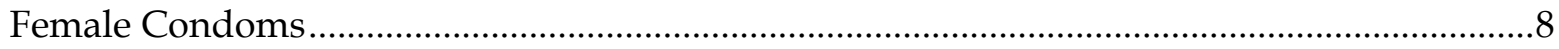

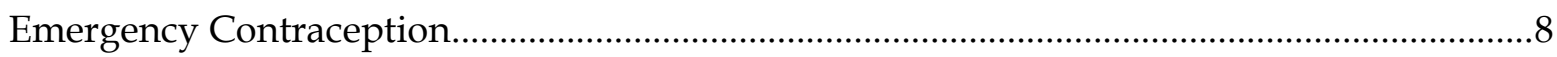

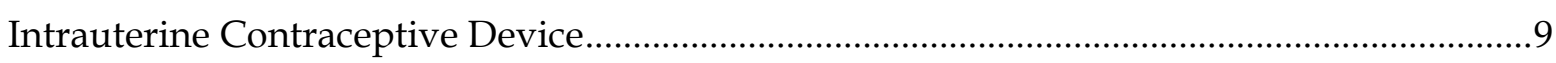

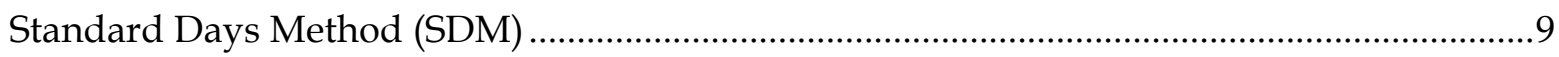

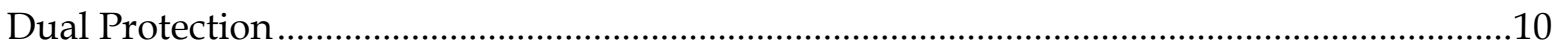

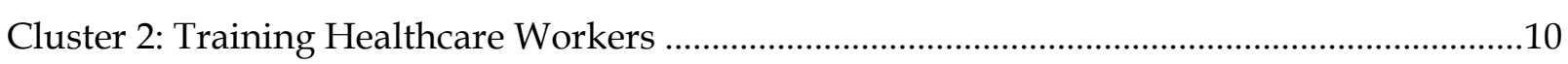

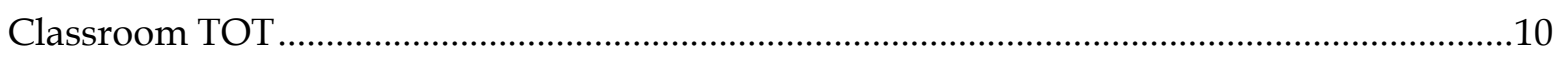

On-Site Self-Directed Learning Program ...................................................................................11

Cluster 3: Linking the Community and the Health Sector ............................................................12

Strengthening Community Linkages .....................................................................................13

Strengthening Linkages within the Health Sector .............................................................13

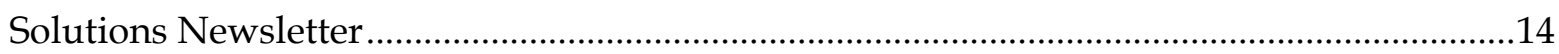

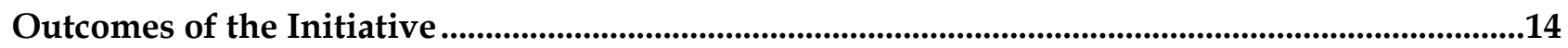

Expanded Contraceptive Choice...............................................................................................14

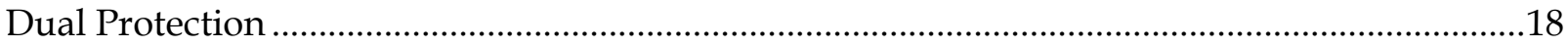

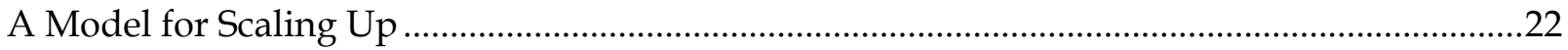

Next Steps: Regional to National Programs ...................................................................................................22 


\section{LIST OF FIGURES}

Figure 1: Conceptual framework for scaling up pilot interventions...................................................

Figure 2: New and continuing contraceptive method users, by quarter........................................15

Figure 3: New contraceptive users as a percentage of population, by province..............................15

Figure 4: New and continuing users, by district......................................................................

Figure 5: Most popular contraceptive methods for new and continuing users ..............................17

Figure 6: Number of new users of the standard days method, by project quarter...........................18

Figure 7: Number of users of dual protection, by project quarter......................................................19

Figure 8: Number of users of dual protection, by district .........................................................20

Figure 9: Methods most frequently combined with condoms for dual protection...........................20

Figure 10: Users of dual protection, by age and project quarter ..................................................21

\section{LIST OF TABLES}

Table 1: Strategy for scaling up the Expanding Contraceptive Choice Project, Zambia....................5

Table 2: Methods offered at participating PRP service delivery points ...........................................7

Table 3: Contraceptive methods offered by participating service delivery points ...........................16 


\section{ABBREVIATIONS}

BTL Bilateral Tubal Ligation

$\mathrm{CBOH} \quad$ Central Board of Health

COEs Centers of Excellence

DHMBs District Health Management Boards

DP Dual Protection

EC Emergency Contraception

ECC Expanding Contraceptive Choice

IRH Institute for Reproductive Health

IUD Intrauterine Device

MIS Management Information Systems

$\mathrm{MOH} \quad$ Ministry of Health

NGOs Non Governmental Organizations

PHO Provincial Health Office

PRP Pilots to Regional Programs

SDLM Self-Directed Learning Manual

SDM Standard Days Method

SDPs Service Delivery Points

STI Sexually Transmitted Infections

TOT Training of Trainers

UNFPA United Nations Population Fund

USAID United States Agency for International Development

WHO World Health Organization 


\section{ACKNOWLEDGEMENTS}

The Pilots to Regional Programs (PRP) Initiative was a project of the Copperbelt Provincial Health District, the Zambian Central Board of Health and the Ministry of Health funded by the United States Agency for International Development (USAID) and the World Health Organization (WHO). Technical support was provided by the Population Council; the introduction of the standard days method was supported by the Institute for Reproductive Health (IRH).

PRP's success can be attributed to the commitment and vision of the wide range of individuals and institutions involved in the project. Dr. Peter Mijere (Copperbelt Provincial Health Office), Dr. Rosemary Sunkutu (Central Board of Health) and Mr. John Skibiak (Population Council) ably guided the initiative as co-investigators, and Mrs. Mary Zama (Population Council) and Mrs. Sabina Miti (Copperbelt Provincial Health Office) facilitated the day-to-day administration of the project.

At the Ministry of Health/ Central Board of Health, Dr. Simon Miti, Dr. Ben Chirwa, Dr. Miriam Chipimo, Dr. Reuben Mbewe, Mr. Roy Maswenyeho and Mrs. Mika Bwembya provided invaluable support and advice. The leadership and foresight of Copperbelt Provincial Health Director Dr. Chandwa Ng'ambi, ensured the initiative's continued success in the face of transition; as did key staff at the Copperbelt Provincial Health Office: Mrs. Mary Hadley, Dr. Chama Chungu, and Mr Edwin Gwai.

We are grateful for the active participation of the eight District Health Management Boards involved in this activity. District Health Directors Mrs. Grace Phiri (Lufwanyama) and Mrs. Colly Sovi (Kalulushi) contributed to the development of the Self-Directed Learning Manuals (SDLM) and Dr. Issac Banda (Mpongwe) was instrumental in the onsite IUD training program. District Family Planning Coordinators Ms. Charity Mulenga (Lufwanyama) and Dorothy Kasongamulilo (Kalulushi) managed SDLM pre-testing.

Recognition must be given to those traditional leaders and their counselors who worked to expand access to reproductive healthcare at the community level, most especially Chiefs Mwinuna, Kalunkumya, Fungulwe, Chietftenesses Lesa, Malembeka, Shimukunami. The members of community health neighborhoods and safe motherhood committees served as invaluable links to the health sector.

Partners Dr. Dyness Kasungami and Mrs. Barbara Hughes (USAID), Dr. Peter Fajans and Mrs. Patricia Kamanga (WHO), Dr. Sarai Malumo (UNFPA) and Mr. Jerry Marcus (IRH) have been tireless and consistent advocates for the initiative, highlighting its successes at national and international fora. We also acknowledge of the support of implementing and technical advisory partners: Planned Parenthood of Zambia, Society for Family Health, World Vision and JHPIEGO, Zambia.

This report was written by Dr. Jill Keesbury (Population Council) with much assistance from the key parties identified above. 


\section{EXECUTIVE SUMMARY}

Between 2002 and 2005, the Pilots to Regional Programs (PRP) initiative was implemented in eight rural and periurban districts of Zambia's Copperbelt region. This initiative worked to scale up the successes of its predecessor, the Expanding Contraceptive Choice Project (ECC), which had been piloted in three districts of the Copperbelt. Implemented by the Zambian Ministry of Health/Central Board of Health in collaboration with the Copperbelt Provincial Health Office and with technical assistance from the Population Council, the PRP initiative had two objectives:

- to expand contraceptive choice and increase the availability of high-quality reproductive health services, especially family planning, for thousands of men and women across Copperbelt Province, and

- to field-test a model for scaling up reproductive health interventions, originally implemented on a pilot or experimental basis.

To achieve these objectives, the initiative developed a conceptual framework that allowed project planners to identify the elements of the ECC program best suited for scaling up. The resulting project was guided by the principle of local autonomy and was structured around three of the most successful ECC activities:

(1) expanding the method mix,

(2) training healthcare workers, and

(3) linking the community with the health sector.

The initiative realized success in all three areas. Contraceptive use steadily increased during the project period, with both new acceptors and continuing users rising 81 percent and 90 percent, respectively. Method mix increased in all project sites, with five of the eight methods in the initiative's "minimal method mix" available at more than 80 percent of all facilities. Three methods (oral contraceptives, injectables, and male condoms) were almost universally available in participating health centers and were among the most popular methods with clients.

Providers' improved competence had an important impact on the initiative's success. Use of family planning methods was found to be higher in areas with dynamic providers and committed supervisors. New methods, such as the standard days method, were especially dependent on the commitment of individual providers. Conversely, dual protection, an option that realized limited gains, was hampered by providers' lack of acceptance.

To ensure providers' competence in low-resource settings, the initiative developed an intensive self-directed learning manual. This training approach was found to be most appropriate for facilities that could not release staff for extended classroom trainings. It was also found to be exceptionally cost-effective, with instructional expenses per person totaling less than half (46 percent) of those of entailed in a similar classroom-based training (US\$373 versus $\$ 803$ ).

PRP's achievements in increasing family planning options and method use demonstrated the usefulness of the conceptual model employed in the design of the project. As a result, the Ministry of Health has recognized this initiative as a "best practice," and is currently exploring options for scaling up nationally. 


\section{INTRODUCTION}

Pilots to Regional Programs (PRP) was a broad-based reproductive health initiative implemented in Zambia's Copperbelt region from 2002 to 2005. The initiative was implemented by the Zambian Ministry of Health/Central Board of Health $(\mathrm{MOH} / \mathrm{CBOH})$ in collaboration with the Copperbelt Provincial Health Office (PHO) and was funded by the United States Agency for International Development (USAID) and the World Health Organization (WHO). Technical assistance was provided by the Population Council, which maintained a project office in the Copperbelt PHO.

Launched in 2002, PRP worked to expand contraceptive method choice and increase the availability of high-quality reproductive health services, especially family planning, in all eight of the Copperbelt's rural and periurban districts. It also sought to field-test a model for scaling up reproductive health interventions that had been implemented on a pilot basis.

This report details the activities of the initiative over its three-year life, highlighting the process of moving to scale and implementing interventions to expand contraceptive choice. It also reviews end-of-project data that demonstrate the initiative's success in increasing contraceptive prevalence throughout the region.

\section{BACKGROUND}

In 1995, the Zambia Ministry of Health undertook a strategic assessment of contraceptive needs using the Strategic Approach to Strengthening Reproductive Health Policies and Programmes developed by the WHO. ${ }^{1}$ Supported by $\mathrm{WHO}$ and the Population Council, the assessment proved pivotal in shaping the future of reproductive health services in Zambia. It identified key health-policy concerns, provided a framework for research on contraceptive introduction, and served as a catalyst for the development of Zambia's first family planning service delivery guidelines. It also influenced the procurement of new contraceptive methods and the phasing out of others, such as high-dose oral contraceptives.

Based on the assessment's recommendations, several pilot studies were eventually carried out that sought to increase the availability of new and/or underused methods, while at the same time using the introduction of those methods as a means to improve the quality of services in general. The largest and by far the most ambitious of these studies, popularly known as the Expanding Contraceptive Choice (ECC) project, took place between 1996 and 2000 among selected health centers in three newly created rural health districts of the Copperbelt Province. The rationale for the study was twofold: the low prevalence of modern contraceptive use and the

\footnotetext{
1 The WHO Strategic Approach is a systematic, three-stage approach for identifying and prioritizing reproductive healthcare needs, for testing practical solutions to those needs, and for bringing to scale the successes, taking into account the lessons learned.
} 
dramatic imbalance in the composition of Zambia's limited method mix. In 1995, contraceptive prevalence of modern methods was only 7 percent, with half of all users opting for the pill and the other half relying primarily on the intrauterine device (IUD) and sterilization. This situation was the result of several factors: the public sector service delivery system was weak, providers' competence was poor, access to services was limited for large segments of the population, and - in contrast with its neighboring countries - injectable contraceptives were virtually nonexistent in the public sector.

At the conclusion of the ECC project, data from service statistics, an internal midterm evaluation, feedback from the three participating health districts, and preand postintervention situation analyses left little doubt that the study had had a major impact on the scope and quantity of services at the 11 participating health centers. Under the leadership of a project manager contracted by the $\mathrm{CBOH} / \mathrm{MOH}$, the pilot project had trained healthcare personnel in the provision of family planning services; it had provided more specialized training in IUD insertion and in the screening and treatment of sexually transmitted infections (STIs), improved counseling tools, and strengthened providers' counseling skills. It had also established referral systems; introduced three new contraceptives - the injectable method DMPA, the female condom, and emergency contraception, and furnished the centers with new supplies and equipment.

At the study's dissemination workshop, participants recommended that the interventions be scaled up throughout all eight of the Copperbelt's rural and periurban health districts. Participants also provided direction as to how the effort should be conducted. They suggested, for example, that the equipment, supplies, and even personnel involved in the pilot study should not be absorbed into routine operations of the Central Board of Health, but rather should be reserved for the scaling up effort. They also recommended that the new contraceptive methods introduced by the pilot study be distributed through the public sector logistics system. Finally, workshop participants called on the Ministry of Health to recognize formally the important role of DMPA in the method mix and support its full incorporation into the service delivery system. Within one month, the $\mathrm{CBOH}$ approved these recommendations and gave a green light to scale up efforts to enhance contraceptive choice and improve quality of care throughout the Copperbelt.

The objectives of this new activity, called the PRP initiative, were twofold:

- to expand contraceptive choice and increase the availability of high-quality reproductive health services, especially family planning, for thousands of men and women across the Copperbelt Province, and

- To field-test a model for scaling up reproductive health interventions that were originally implemented on a pilot or experimental basis. 


\section{THE CONCEPTUAL FRAMEWORK FOR SCALING UP}

As a first step, project planners were faced with the task of developing a strategy for scaling up the original ECC project. They realized that replicating every aspect of the previous study was not feasible or even appropriate. They also recognized that scaling up was a large undertaking: the number of service delivery points, for example, would increase from 11 to at least 37, while the population of the districts covered would jump from 238,000 to roughly a million. At the same time, they acknowledged that key aspects of the scaling up process remained unclear: Which activities would be scaled up? Who would do what? And how and when would the scaling up take place? The team came to realize that these issues were not just isolated sets of problems, but were interrelated and, in fact, encompassed the central programmatic issues and challenges associated with scaling up in general.

To address these concerns, the team developed a conceptual framework to guide the scaling up process. Illustrated in Figure 1, this framework envisioned the three main questions guiding the team as axes on a triangle. Each point corresponded to one of the three key concerns: the content of intervention activities (what was to be scaled up); the breadth of scaling up over time and place (where and when it would be done); and the organizational implications of the scaling up process (who would do what and how, and by what mechanisms). In between these axes lay the areas for contestation and negotiation, such as how to maintain high quality (content) while increasing quantity (process). ${ }^{2}$

\section{Figure 1: Conceptual framework for scaling up pilot interventions}

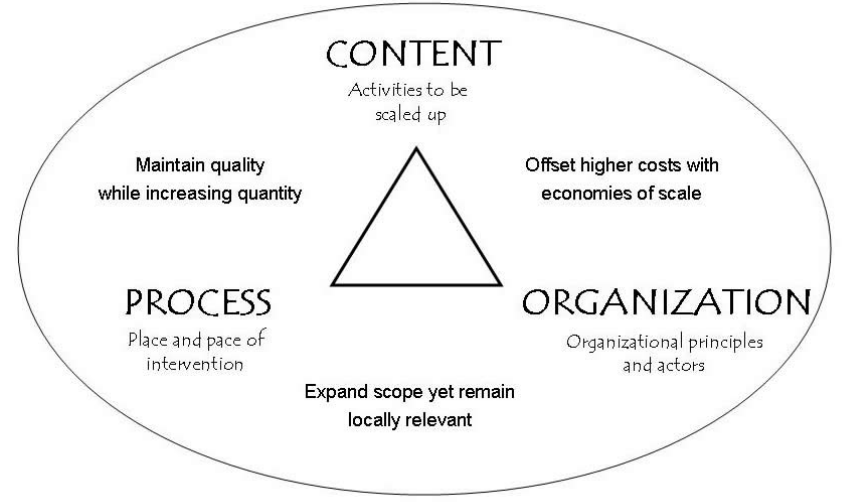

Project planners used this framework to think through the issues related to scaling up more systematically. The intervention strategy outlined below is the result of this process.

\footnotetext{
2 For a more complete discussion of this model, refer to Skibiak et al. 2006. "Expanding contraceptive choice and improving quality of care in Zambia's Copperbelt: Moving from pilot projects to regional programmes." In Scaling up Health Service Delivery: From Pilots to Policies and Programmes. Eds. Simmons et al. Geneva: World Health Organization.
} 


\section{THE INTERVENTION STRATEGY}

The strategy that planners developed to scale up ECC activities, outlined in Table 1, closely reflected the conceptual framework. They recognized that scaling up from the three original ECC sites to all eight of the Copperbelt's rural and periurban districts would require the flexible, phased approach made possible by this model. In terms of context, the team identified three clusters of ECC activities that were critical for replicating in the PRP scaling up effort:

(1) expanding the contraceptive method mix,

(2) training healthcare workers, and

(3) linking the community with the health sector.

Activities began with the establishment of 21 "centers of excellence" (COEs) in all the districts that provided a full range of methods, and by a training of trainers (TOT) for a group of healthcare workers in each district. Efforts then expanded into nonCOE sites, where TOTs trained their peers to provide high-quality services, make proper referrals, and strengthen linkages with surrounding communities.

Finally, the team focused on creating stronger horizontal linkages among districts, greater local ownership, and a consolidation of management roles and responsibilities. Management responsibility for the initiative fell to the Director of the Copperbelt PHO and a team of technical advisers, led by the Population Council project manager. Working hand in hand with coordinators designated by each participating health district, the advisers helped design and support activities in each of the three content areas: expanding contraceptive choice, training, and the establishment of community outreach. From the start, program implementation became a collaborative effort between the province, which provided technical and financial support, and the districts as the local coordinating and implementing agencies.

Over time, however, the role of the PHO diminished as districts gradually assumed responsibility for the content and pace of the scaling up process. From the reflection and analysis phase onward, the districts determined which interventions would be expanded and how the expansion would be conducted. As districts recognized the advantages of reducing costs and maximizing economies of scale, they began to take control of management decisions, pool resources, and share expenses. The PHO continued to provide technical and financial support, but the organizational structure of PRP became less centralized. Rather than imposing a uniform or standardized implementation model, the scaling up approach applied a threephased process by which districts agreed to a common set of quality standards while maintaining the flexibility to decide, based on local needs and conditions, the most appropriate means to achieve these standards and the relative investment they intend to make to do so. 


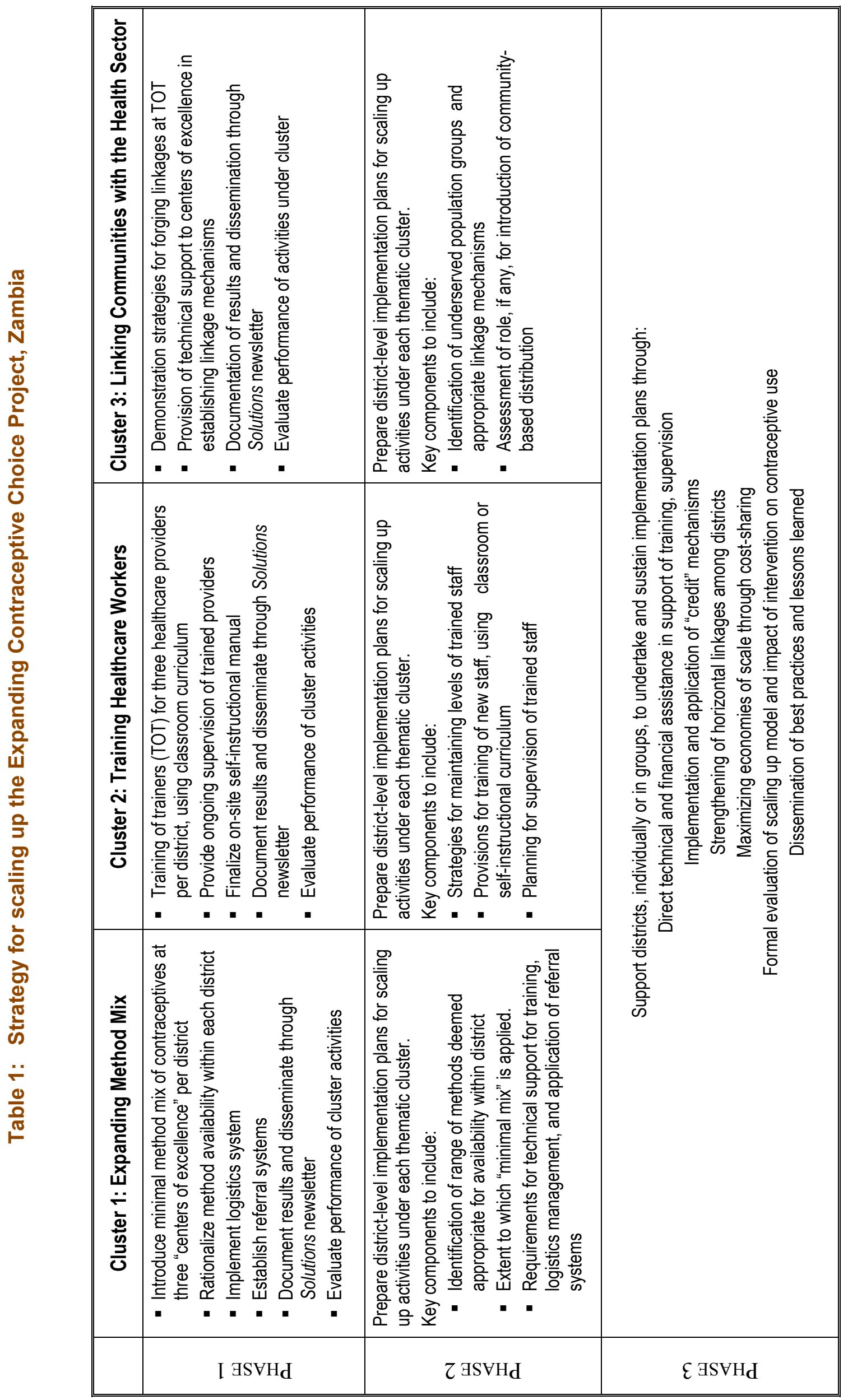




\section{INTERVENTION ACTIVITIES}

Although the intervention was conducted in phases, its activities are best understood in terms of the three clusters identified in Table 1. Reviewing the key efforts taken to implement each of these clusters provides useful insight into the structure and scope of the initiative.

\section{Cluster 1: Expanding the Method Mix}

All participating healthcare facilities maintained a common "minimal method mix" intended to ensure that every potential or actual family planning client had access to a broad range of contraceptive methods. ${ }^{3}$ Although many service delivery points (SDPs) could provide all the methods on site, other less-equipped facilities referred clients' to centers where they could have access to the full range of methods in the mix.

Districts determined for themselves which method or brands would be made available at each SDP. At the outset of the study, method choice in most facilities not served by ECC remained limited to Microgynon (a brand of oral contraceptive) and male condoms. To ensure the availability of the minimal method mix, new methods were introduced, including the female condom, emergency contraception (EC), the standard days method (SDM) ${ }^{4}$; and the provision of traditionally underused methods, such as injectables, the intrauterine device (IUD) and bilateral tubal ligation (BTL), was strengthened. Two districts implemented a program of mobile IUD services. Table 2 provides an overview of the range of methods offered at each SDP.

Because only a few facilities offered the full range of contraceptives in the minimal method mix, establishing an effective referral system was important. At the project's outset, only a small number of referred clients received services at the referral centers. A number of barriers to effective referral were identified:

- the absence of a functional feedback mechanism from the referral center to the referring facility,

- the failure of referring facilities to provide patients with referral forms,

- unauthorized charges to clients for services that should be offered free of charge, and

- lack of mechanisms or procedures to identify specific weaknesses in the system.

District-level authorities, housed in District Health Management Boards (DHMBs), responded to these challenges by developing standardized referral forms for use at all SDPs. Many districts adopted additional strategies. COEs in Luanshya, Mufulira, Chingola, and Chililabombwe sought meaningful feedback on their referred clients.

3 The minimal method mix includes both male and female condoms; a dedicated emergency contraceptive pill or combined oral contraceptives repackaged for emergency contraceptive use; the CuT380 IUD; Depo-Provera®; Microgynon; Microlut; bilateral tubal ligation (BTL); and the standard days method.

4 The standard days method is a form of natural family planning based on the principle that women can become pregnant only on certain days of the menstrual cycle. Using a simple, color-coded string of beads, called "CycleBeads, ${ }^{\circledR "}$ a woman can determine when those days are, so that she and her partner can avoid having sex during that period. 
The Chililabombwe, Chingola, and Mufulira DHMBs established referral committees to address weaknesses when they arise. Other districts, including Mpongwe, employed visiting doctors to relay feedback forms from referral hospitals to referring facilities.

Table 2: Methods offered at participating PRP service delivery points

\begin{tabular}{|c|c|c|c|c|c|c|c|c|c|}
\hline District & Service delivery point & Male condom & Female condom & Pill & Injectables & IUD & BTL & EC & SDM \\
\hline \multirow[t]{3}{*}{ Chililabombwe } & Kakoso* & $\checkmark$ & $\checkmark$ & $\checkmark$ & $\checkmark$ & $\checkmark$ & $\checkmark$ & $\checkmark$ & $\checkmark$ \\
\hline & Lubengele* & $\checkmark$ & $\checkmark$ & $\checkmark$ & $\checkmark$ & $\checkmark$ & $\checkmark$ & $\checkmark$ & $\checkmark$ \\
\hline & Chimfunshi & $\checkmark$ & & $\checkmark$ & $\checkmark$ & $\mathrm{R}$ & $\mathrm{R}$ & & \\
\hline \multirow[t]{2}{*}{ Chingola } & Chiwempala* & $\checkmark$ & $\checkmark$ & $\checkmark$ & $\checkmark$ & $\mathrm{R}$ & $\mathrm{R}$ & $\checkmark$ & $\checkmark$ \\
\hline & Muchinshi* $^{*}$ & $\checkmark$ & $\checkmark$ & $\checkmark$ & $\checkmark$ & $\checkmark$ & $\checkmark$ & $\checkmark$ & $\checkmark$ \\
\hline \multirow[t]{6}{*}{ Mufulira } & Murundu* & $\checkmark$ & $\checkmark$ & $\checkmark$ & $\checkmark$ & $\mathrm{R}$ & $\mathrm{R}$ & $\checkmark$ & $\checkmark$ \\
\hline & Kamuchanga* & $\checkmark$ & $\checkmark$ & $\checkmark$ & $\checkmark$ & $\mathrm{R}$ & $\mathrm{R}$ & $\checkmark$ & $\checkmark$ \\
\hline & Clinic $5^{*}$ & $\checkmark$ & $\checkmark$ & $\checkmark$ & $\checkmark$ & $\checkmark$ & $\checkmark$ & $\checkmark$ & $\checkmark$ \\
\hline & Chibolya & $\checkmark$ & $\checkmark$ & $\checkmark$ & $\checkmark$ & $\mathrm{R}$ & $\mathrm{R}$ & $\checkmark$ & $\checkmark$ \\
\hline & Kawama & $\checkmark$ & & $\checkmark$ & $\checkmark$ & $\mathrm{R}$ & $\mathrm{R}$ & $\checkmark$ & $\checkmark$ \\
\hline & Mokambo & & $\checkmark$ & $\checkmark$ & $\checkmark$ & $\mathrm{R}$ & $\mathrm{R}$ & & \\
\hline \multirow[t]{6}{*}{ Kalulushi } & Ichimpe* & $\checkmark$ & $\checkmark$ & $\checkmark$ & $\checkmark$ & $\mathrm{M}$ & $\mathrm{R}$ & $\checkmark$ & $\checkmark$ \\
\hline & Kalulushi* & $\checkmark$ & $\checkmark$ & $\checkmark$ & $\checkmark$ & $\checkmark$ & $\mathrm{R}$ & $\checkmark$ & $\checkmark$ \\
\hline & Chibuluma* & $\checkmark$ & $\checkmark$ & $\checkmark$ & $\checkmark$ & $\mathrm{M}$ & $\mathrm{R}$ & $\checkmark$ & $\checkmark$ \\
\hline & Chambishi & $\checkmark$ & $\checkmark$ & $\checkmark$ & $\checkmark$ & $\mathrm{M}$ & $\mathrm{R}$ & $\checkmark$ & $\checkmark$ \\
\hline & Chati & $\checkmark$ & $\checkmark$ & $\checkmark$ & $\checkmark$ & $\mathrm{M}$ & $\mathrm{R}$ & $\checkmark$ & $\checkmark$ \\
\hline & Lukoshi & $\checkmark$ & $\checkmark$ & $\checkmark$ & $\checkmark$ & $M$ & $\mathrm{R}$ & $\checkmark$ & $\checkmark$ \\
\hline \multirow[t]{6}{*}{ Lufwanyama } & Shimukunami* & $\checkmark$ & $\checkmark$ & $\checkmark$ & $\checkmark$ & $\mathrm{R}$ & $\mathrm{R}$ & $\checkmark$ & $\checkmark$ \\
\hline & Lumpuma* & $\checkmark$ & $\checkmark$ & $\checkmark$ & $\checkmark$ & $\mathrm{R}$ & $\mathrm{R}$ & $\checkmark$ & $\checkmark$ \\
\hline & Kite $^{*}$ & $\checkmark$ & $\checkmark$ & $\checkmark$ & $\checkmark$ & $M$ & $\mathrm{R}$ & $\checkmark$ & $\checkmark$ \\
\hline & Fungulwe & $\checkmark$ & $\checkmark$ & $\checkmark$ & $\checkmark$ & $\mathrm{R}$ & $\mathrm{R}$ & $\checkmark$ & $\checkmark$ \\
\hline & Mukutuma & $\checkmark$ & $\checkmark$ & $\checkmark$ & $\checkmark$ & $\mathrm{R}$ & $\mathrm{R}$ & $\checkmark$ & \\
\hline & Chikabuke & $\checkmark$ & $\checkmark$ & $\checkmark$ & $\checkmark$ & $\mathrm{R}$ & $\mathrm{R}$ & $\checkmark$ & \\
\hline \multirow[t]{4}{*}{ Luanshya } & Chibolya* & $\checkmark$ & $\checkmark$ & $\checkmark$ & $\checkmark$ & $\checkmark$ & & $\checkmark$ & $\checkmark$ \\
\hline & Kafubu Block ${ }^{*}$ & $\checkmark$ & $\checkmark$ & $\checkmark$ & $\checkmark$ & $\mathrm{R}$ & $\mathrm{R}$ & $\checkmark$ & $\checkmark$ \\
\hline & Mpatamato* & $\checkmark$ & $\checkmark$ & $\checkmark$ & $\checkmark$ & $\mathrm{R}$ & $\mathrm{R}$ & $\checkmark$ & $\checkmark$ \\
\hline & St Mary's & $\checkmark$ & & $\checkmark$ & $\checkmark$ & $\mathrm{R}$ & $\mathrm{R}$ & & $\checkmark$ \\
\hline \multirow[t]{7}{*}{ Masaiti } & Masaiti Council ${ }^{*}$ & $\checkmark$ & $\checkmark$ & $\checkmark$ & $\checkmark$ & $R$ & $\mathrm{R}$ & $\checkmark$ & $\checkmark$ \\
\hline & Mishikishi* & $\checkmark$ & $\checkmark$ & $\checkmark$ & $\checkmark$ & $\checkmark$ & $\checkmark$ & $\checkmark$ & $\checkmark$ \\
\hline & Njelemani* $^{*}$ & $\checkmark$ & $\checkmark$ & $\checkmark$ & $\checkmark$ & $\mathrm{R}$ & $\mathrm{R}$ & $\checkmark$ & $\checkmark$ \\
\hline & Chikumbi & $\checkmark$ & & $\checkmark$ & $\checkmark$ & $\mathrm{R}$ & $\mathrm{R}$ & & \\
\hline & Kafulafuta & $\checkmark$ & & $\checkmark$ & $\checkmark$ & $\mathrm{R}$ & $\mathrm{R}$ & $\checkmark$ & \\
\hline & Kambowa & $\checkmark$ & & $\checkmark$ & $\checkmark$ & $\mathrm{R}$ & $\mathrm{R}$ & & \\
\hline & Masaiti Boma & $\checkmark$ & $\checkmark$ & $\checkmark$ & $\checkmark$ & $\mathrm{R}$ & $\mathrm{R}$ & $\checkmark$ & \\
\hline \multirow[t]{3}{*}{ Mpongwe } & Ipumbu* & $\checkmark$ & $\checkmark$ & $\checkmark$ & $\checkmark$ & $\mathrm{R}$ & $\checkmark$ & $\checkmark$ & $\checkmark$ \\
\hline & Mikata* & $\checkmark$ & & $\checkmark$ & $\checkmark$ & $\checkmark$ & $R$ & $\checkmark$ & $\checkmark$ \\
\hline & St Theresa & $\checkmark$ & & $\checkmark$ & $\checkmark$ & $\checkmark$ & $\checkmark$ & & $\checkmark$ \\
\hline
\end{tabular}

${ }^{*}$ Centers of excellence

$\mathrm{BTL}=$ Bilateral tubal ligation. $\quad \mathrm{EC}=$ Emergency contraception. $\mathrm{SDM}=$ Standard days method.

$\mathrm{R}=$ Referrals offered. $\mathrm{M}=$ Mobile IUD provision. 
The implementation of the minimal method mix was a gradual process, especially with regard to new methods. In some cases, methods had to be procured or systems established for appropriate referral. Other methods proved to be so popular that they created demand at SDPs not involved in the study. The most notable of such experiences are outlined below.

\section{Female Condoms}

As one of the methods in the minimal method mix, the PRP initiative worked to make female condoms available at all COEs. At the outset of the study, female condoms were not as readily available as male condoms, largely because only limited supplies of this method have been available from Medical Stores, Ltd., the parastatal supplier of public-sector contraceptive commodities.

In October 2002, the initiative distributed eight female condoms to each COE to generate awareness of the method. In response to the demand from providers and clients, the initiative later bought two boxes of female condoms for 19 of the 21 COEs to be resold as a socially marketed product. (At the time of distribution, two COEs, Kakoso and Lubengele, already had their own stocks.) Overall, the demand for these socially marketed female condoms was disappointing. Providers claimed that potential clients had difficulty rationalizing the purchase of the female condom, when they knew that the male condom was available for free. Also, according to some providers, the 250 Kwacha_price for two female condoms was too high for most rural women.

As a result of poor sales, the DHMBs decided that they would henceforth provide female condoms free of charge, as they did with other methods. This shift in pricing policy brought about a dramatic increase in the use of the female condoms - so that DHMBs had to procure stocks on their own or obtain them from other NGOs.

\section{Emergency Contraception}

During the original ECC study, all participating healthcare facilities had access to a dedicated EC pill, which at the time, was available in Zambia under the brand name PC-4. ${ }^{5}$ In 2000, Zambia's PC-4 stocks expired, and all remaining samples were destroyed. No new stocks were ordered, so that at the outset of the PRP project, no dedicated EC pill of any kind was available anywhere in Zambia in the public or private sectors.

The project was unable to restock a dedicated product because the new formulation, Postinor 2, was not yet registered with the country's Pharmaceutical Regulatory Authority. Instead, the Yuzpe method of EC was included in project activities. 6 Although a dedicated product is preferable in terms of efficacy and side effects,

\footnotetext{
5 In 1995, 50,000 units of PC-4 were procured by DFID (then ODA) for public-sector use. Between 1998 and 2000, the Population Council, University Teaching Hospital, CARE, and the Society for Family Health sponsored three operations research studies, each designed to address a critical service-delivery issue relating to the introduction of EC services

6 The Yuzpe method involves taking a certain number of combined oral contraceptives (the number depending on the pill brand's hormonal content) within 72 hours of unprotected sex, followed by the same number of pills 12 hours later.
} 
evidence suggests that the Yuzpe method is more sustainable in low-resource settings. ${ }^{7}$ To simplify provision, the project prepared 1,841 units of repackaged EC. These packets consisted of eight Microgynon pills and two male condoms.

\section{Intrauterine Contraceptive Device}

Because most participating facilities did not have the staff or infrastructure necessary to perform IUD insertions, the project focused on increasing IUD access through outreach or referral.

The outreach strategy entailed the use of "roving" providers to perform insertions at healthcare facilities where no permanent, full-time trained staff are available. Under this arrangement, clients desiring an IUD underwent screening (personal histories, pelvic exams, counseling) at their local health center and were scheduled for an insertion during the next visit by the trained provider. In the meantime, they were provided with a supply of condoms for temporary use and combined oral contraceptives or progestin-only pills.

Providers from two DHMBs performed IUD insertions on an outreach basis. Efforts to introduce outreach services at Chililabombwe, Kalulushi, and Mpongwe DHMBs were met with limited success. Based on interviews with PRP staff, three reasons were identified:

- Many clients found it difficult to return to healthcare facilities for fixed appointments.

- Most clients preferred a method they could obtain immediately, rather than one requiring a return visit.

- Often, providers did not present the IUD as an option to their clients. They tended to emphasize those methods that they themselves could provide, perhaps because they felt more comfortable discussing such methods.

Nevertheless, efforts to improve the referral system continued, with PRP staff facilitating discussions between the referring centers, DHMBs, and the referral facilities. Teamwork between the referring and referral SDP staff improved, and providers were encouraged to use District or $\mathrm{MOH} / \mathrm{CBOH}$ Health Information Management Systems.

\section{Standard Days Method (SDM)}

With technical support from Georgetown University's Institute for Reproductive Health, the SDM proved to be a popular addition to districts' method mix, even among SDPs that were not participating in the project. Two faith-based facilities specifically sought out PRP assistance to introduce the method. At one of the health centers, community responsiveness to the SDM prompted the center to begin introducing other contraceptives, including modern methods.

\footnotetext{
7 Camp, Sharon. 1998. "The status of dedicated products." Journal of the American Medical Women's Association 53(5), Supplement 2: 225-229.
} 


\section{Dual Protection}

One notable trend that emerged from the original ECC study was the decline in exclusive condom use for family planning purposes. As women and men were presented with more contraceptive options, pre-intervention percentages of condoms and pills (the only two methods available at the time) predictably declined in favor of the new alternatives.

Although procurement records and other commodity logistics data showed that overall condom use in the participating districts had increased during the ECC study, the existing MIS systems were incapable of capturing condom use when condoms were employed in conjunction with another contraceptive. In other words, no provisions were made for measuring dual-method use.

To address this gap in the service delivery system and to provide DHMBs with an objective, reliable indicator of success in promoting dual protection, the PRP initiative developed a user-friendly tool for enabling healthcare providers to: (1) identify the range of scenarios under which clients might use dual methods, (2) employ standardized criteria for classifying users as dual-method users, and (3) apply a simple MIS system for disaggregating dual- and single-method users. As study results show, however, this tool ultimately demonstrated the limited popularity of dual protection among clients.

\section{Cluster 2: Training Healthcare Workers}

In the ECC study, the introduction of new methods entailed a package of interventions that included community sensitization, commodity distribution, and technical backup for providers. The training of healthcare workers, however, formed the basis for virtually every intervention activity undertaken.

For the PRP initiative, the role of training remained equally important. In contrast to the ECC study, which relied almost exclusively on a traditional classroom approach, the PRP initiative employed two approaches. One was the traditional approach; the other was the application of an innovative on-site self-directed learning program initially developed during the ECC study for rural health workers' use.

\section{Classroom TOT}

At the outset of the project, 22 healthcare providers (two men and 20 women) attended a four-week course for trainers of trainers (TOT). Participants were drawn from each of the participating COEs, and from the corresponding DHMB offices. The course covered a wide range of reproductive health topics, reviewed each method in the minimal mix, and addressed teaching and communication skills. Pre- and post-test scores indicated that participants' knowledge improved by a mean of 40 percent. Each trainer was given a practical skills assessment to gauge clinical competency. 


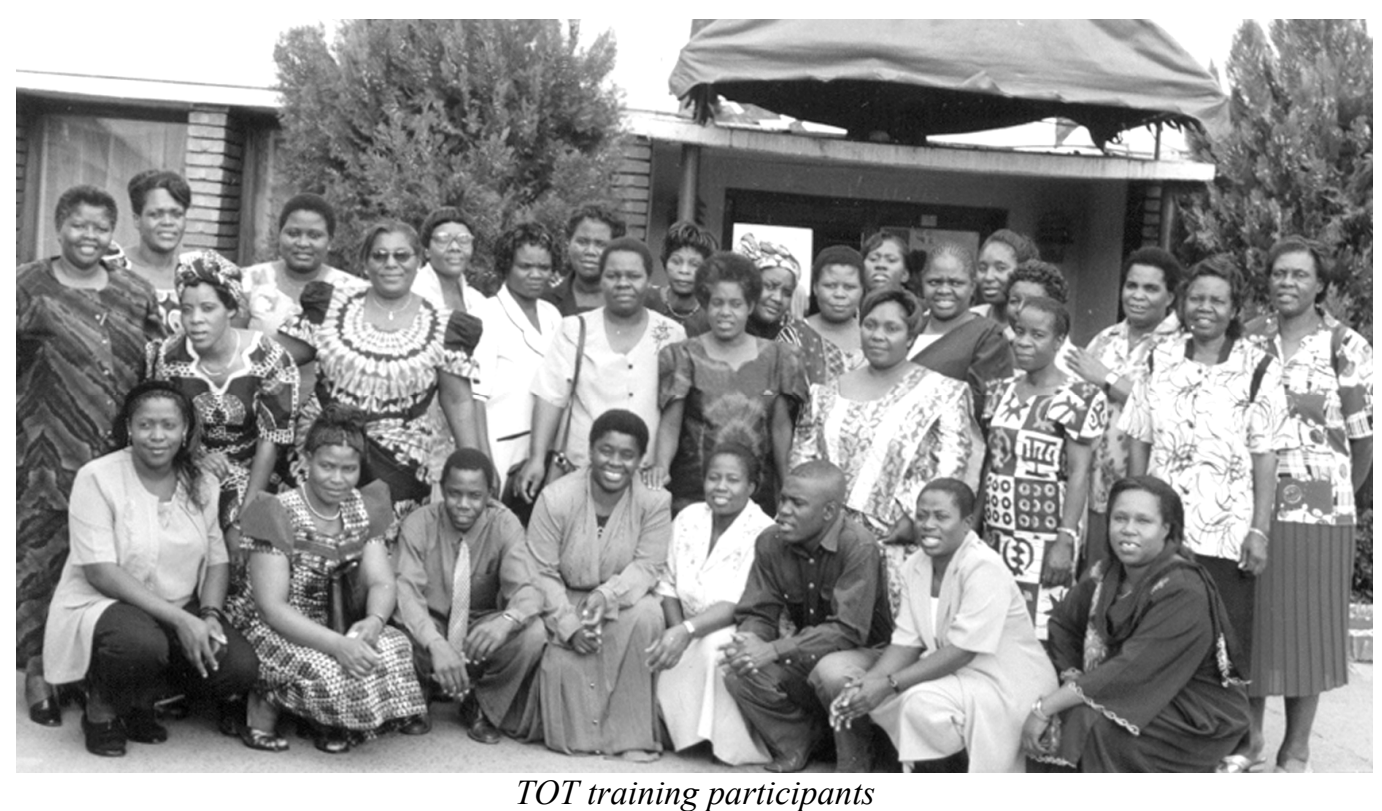

In slightly more than a year, these TOTs had trained more than 45 other clinic-based providers, community-based distributors, and community health workers in the delivery of family planning methods. This increase in the number of trained providers contributed significantly to the rising number of family planning acceptors, and stands in sharp contrast with the original ECC study during which, one year into the project, attrition and death had reduced the number of trained providers by almost half.

\section{On-Site Self-Directed Learning Program}

In the ECC study, high turnover and attrition among healthcare providers prompted the development of a new approach to training, one better suited to the realities of working in a resource-poor rural environment. The product of that effort was the development of a self-directed learning program, at the core of which was the on site Self-Directed Learning Manual (SDLM) for training providers at small, typically oneperson, healthcare facilities.

The SDLM is a distance-learning tool that local healthcare providers can use to master the key elements of family planning service provision. ${ }^{8}$ Under the program, providers completed assigned readings (both from the manual and from selected supplementary reference materials ${ }^{9}$ ) and other exercises at their own pace. These lessons were supplemented routinely by supervisory visits carried out by PRP and/or DHMB staff. Using a supervisory tool developed to accompany the manual, the visiting supervisor reviewed progress, checked over written exercises, demonstrated new skills, observed providers practicing newly learned skills, and provided other necessary support. The

\footnotetext{
8 The manual includes separate chapters on the following topics: national policies and strategies relating to reproductive health; beliefs, traditions, and taboos; adolescents' reproductive health; men's participation in reproductive health services; infection prevention and control; quality of care; strategies for implementing family planning at the community level; counseling techniques; how to conduct family planning histories and physical exams; and the essentials of contraceptive technology.

9 Additional materials include: Integrated Technical Guidelines for Frontline Workers (CBOH 1997); Strategies and Guidelines for Family Planning in Reproductive Health (MOH 1997); and Essentials of Contraceptive Technology, A Handbook for Clinic Staff (Hatcher, R.A. et al. 1997. Baltimore: Population Information Program Center, The Johns Hopkins School of Public Health).
} 
program was designed to be completed in about ten weeks, although timing varied in practice, depending on the providers' motivation, their availability; and the feasibility of regular supervisory visits.

Overall, the program demonstrated that the self-directed approach was as comprehensive and cost-effective as a classroom-based workshop.

- Virtually all of the topics addressed in the intensive three-week classroom-based TOT workshop were covered in the SDLM, and post-tests demonstrated that participants' knowledge and skill levels increased by the same percentage for both training modalities.

Perhaps most significant of all, the training cost per person amounted to less than half (46 percent) that of the classroom-based workshop (US\$373 versus \$803). Cost savings were realized across the board, including reductions in food and lodging, but do not account for additional on-site supervisory expenses.

Despite its advantages, SDLM was not without drawbacks.

- The time required for training was longer than that for the classroom approach because the trainers were required to visit trainee sites. The pace of learning is largely dictated by the trainees' motivation, their ability to learn, and their free time to devote to learning.

- Logistics and vigilant supervision are critical. Careful planning is necessary to ensure that transportation, supplies, and equipment are available so that the supervisor can reach sites and teach practical skills.

Such factors notwithstanding, SDLM is certainly a viable alternative where money is in shorter supply than time.

\section{Cluster 3: Linking the Community and the Health Sector}

Although training is vital to improving providers' competence, the success of the ECC study hinged on its ability to establish strong community linkages. Indeed, the study's success at "breaking down clinic walls" that made it possible to extend the benefits of expanded choice and high-quality care to the community and DMHB levels. The innovative use of chief's tours to disseminate information about reproductive health; the active involvement of project staff in community-based sensitization meetings; the revitalization of community-based neighborhood health groups, "safe motherhood committees," and "circles of friends;" and the publication of newsletters to share healthcare providers' experiences - all of these mechanisms had a profound effect on forging linkages among community institutions, between the community and the formal health sector, and even within the health sector. The PRP initiative established new linkages between communities and health centers, using strategies initially adopted during the ECC study. 


\section{Strengthening Community Linkages}

TOTs initiated the process of linking health centers with the communities they serve. They conducted sensitization meetings at each of the COEs, soliciting discussion and providing guidance on strategies for building better community linkages. Project staff also met health-center staff on a monthly basis to build capacity in developing healthrelated community-sensitization activities and to conduct health-education sessions. In addition, COE and PRP staff solicited community feedback on the usefulness of the meetings in addressing people's health concerns. To ensure continuity and ownership of PRP activities by the $\mathrm{CBOH}$, efforts were made to integrate such activities into annual workplans and performance reviews at the district and provincial levels.

Efforts to promote community ownership quickly took hold. By the project's second quarter, 18 of the 21 communities reached by the TOTs had begun conducting their own sensitization meetings - including special meetings with groups of youth, couples, and men. Even more impressive was the outpouring of support from these communities, which contributed both food and soft drinks to the events.

DHMBs reported that PRP sensitization efforts encouraged communities to take on greater responsibility for their own health issues. Masaiti DHMB, for example, noted that these meetings played a key role in garnering community support for adolescent reproductive health services. Initially, the DHMB encountered some resistance to the establishment of youth-friendly services, but after they explained to local leaders the negative consequences of neglecting this group's needs, communities changed their opinions and became supportive of such services.

By the end of the project, a number of thematic community discussion groups were active. These included safe motherhood and neighborhood health committees, male motivator groups, circles of friends, youth-friendly corners, peer educators, and other community health workers, to name but a few. By winning the support of chiefs and community leaders, PRP has used existing social structures successfully to communicate important information about contraceptive methods and adolescent reproductive health. PRP also worked with traditional counselors, known locally as ifumbusa, to promote family planning among young people. This strategy proved to be extremely effective, as traditional counselors were able to integrate reproductive health themes into post-puberty, premarital, and marital counseling.

\section{Strengthening Linkages within the Health Sector}

In addition to reinforcing the linkages between health centers and the communities they serve, the PRP initiative also actively encouraged districts to work together, share information, and achieve common goals. In the original ECC study, operational relationships were mainly vertical - between the individual districts and the $\mathrm{CBOH}$. PRP, by contrast, sought to reinforce horizontal linkages among the districts themselves. 
During the project's second and third phases, interdistrict collaboration became a hallmark of activities. The project convened regular interdistrict meetings to allow DHMBs to share their accomplishments and to encourage them to solicit input from their colleagues. Districts also planned to conduct individual assessments upon which they based further scaling up activities.

\section{Solutions Newsletter}

The project also produced three issues of the Solutions newsletter, originally published under the ECC study. Solutions served as a popular medium for communicating the challenges associated with the PRP initiative and documenting the ways healthcare providers, DHMB managers, and communities have managed to address them. The publication was targeted to program implementers, and was disseminated widely at the national, provincial, district, and health-center levels. Copies also were distributed nationally to health-related collaborating agencies, donor agencies, and provincial and district health offices.

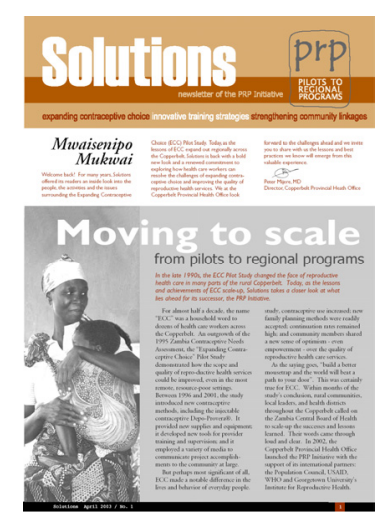

\section{OUTCOMES OF THE INITIATIVE}

Final project data demonstrate that the activities outlined above enabled the initiative to achieve its dual objectives. It increased the number of family planning users who took advantage of a broader range of methods and provided a model for scaling up nationally.

\section{Expanded Contraceptive Choice}

Ultimately, the success of the initiative is measured by the number of people who began or continued to use family planning methods during the life of the project. This one indicator captures all aspects of the program, including expanded client choice, providers' improved competency, and increased community awareness. If all of these elements worked in harmony, the project hypothesized, contraceptive use across the province would increase. As indicated in Figure 2, the project realized such an increase in acceptors, with a steady 81 percent rise in new users and an almost 90 percent jump in continuing users. 
Figure 2: New and continuing contraceptive method users, by quarter

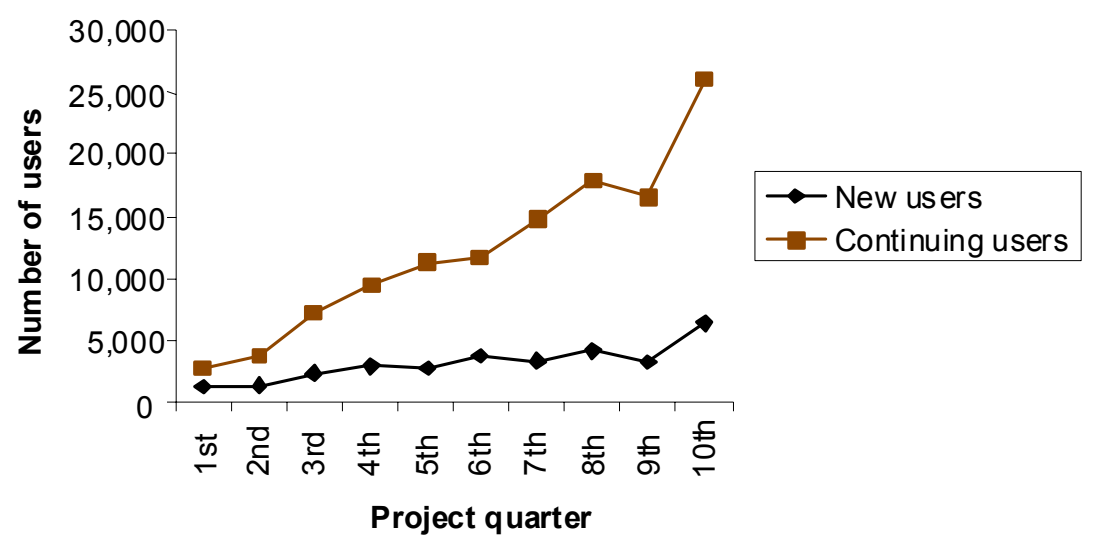

The project's success is also reflected on the national level. As Figure 3 demonstrates, the proportion of new contraceptive users in the Copperbelt exceeded those found in any of the country's other rural and periurban provinces. ${ }^{10}$ On average, the percentage of new acceptors in the Copperbelt was 1.56 times the average of other provinces (3.76 percent vs. 2.41 percent). Differences in trends without accounting for population weight show even higher performance for the Copperbelt in comparison to other provinces. Similar patterns exist for continuing contraceptive use during the project period, with the Copperbelt also leading these provinces in user retention.

Figure 3: New contraceptive users as a percentage of population, by province

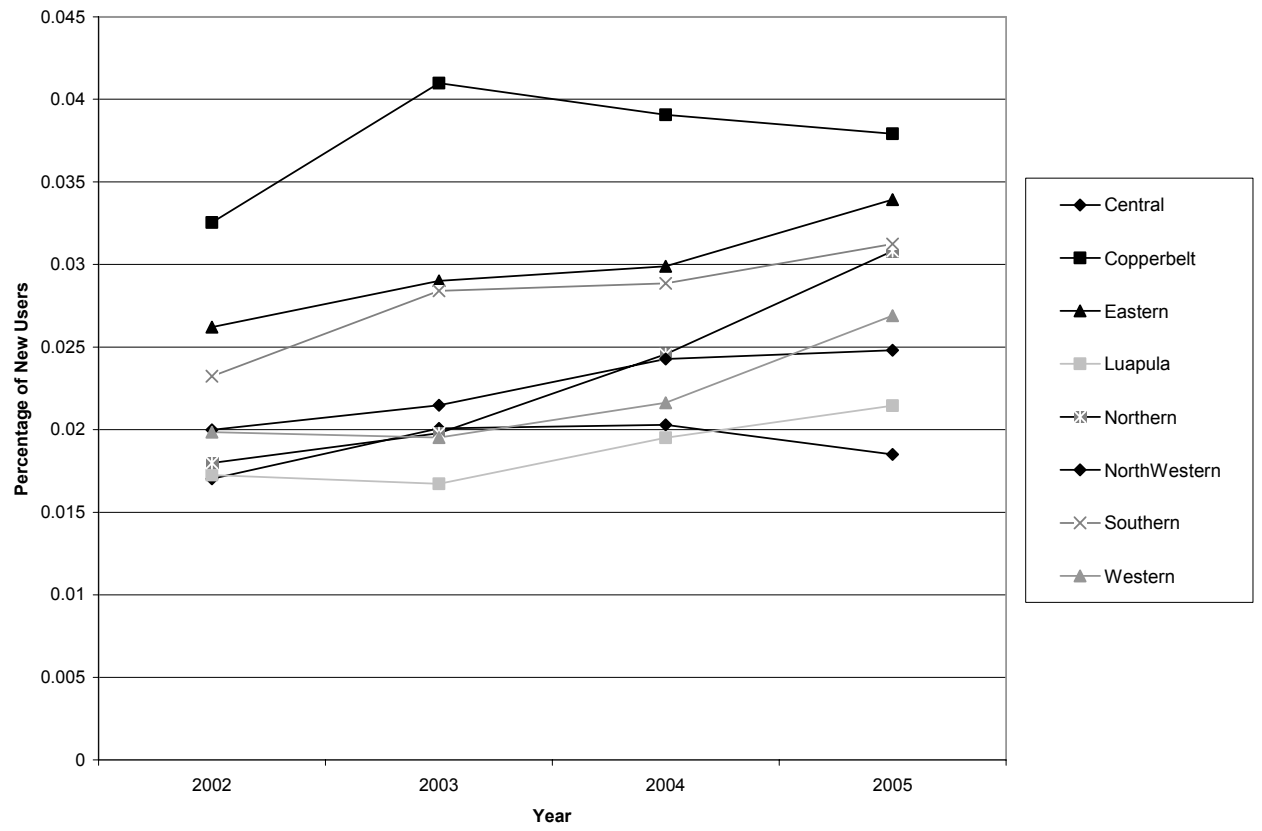

Source: Ministry of Health, Zambia

10 This analysis includes eight of the country's urban and periurban provinces; one province, the capital city of Lusaka, is excluded because as an urban area, its socioeconomic and service-delivery environments are markedly different from those of the project areas and, consequently, are not directly comparable. 
Much of the Copperbelt's success was due to the active support of DHMBs and to the efforts of district coordinators, TOTs, and community members. The highestperforming districts, identified in Figure 4, benefited from the contributions of dynamic individuals and institutions. This outcome highlights a key finding of the study, that human inputs are as important as material and technical contributions.

Figure 4: New and continuing users, by district

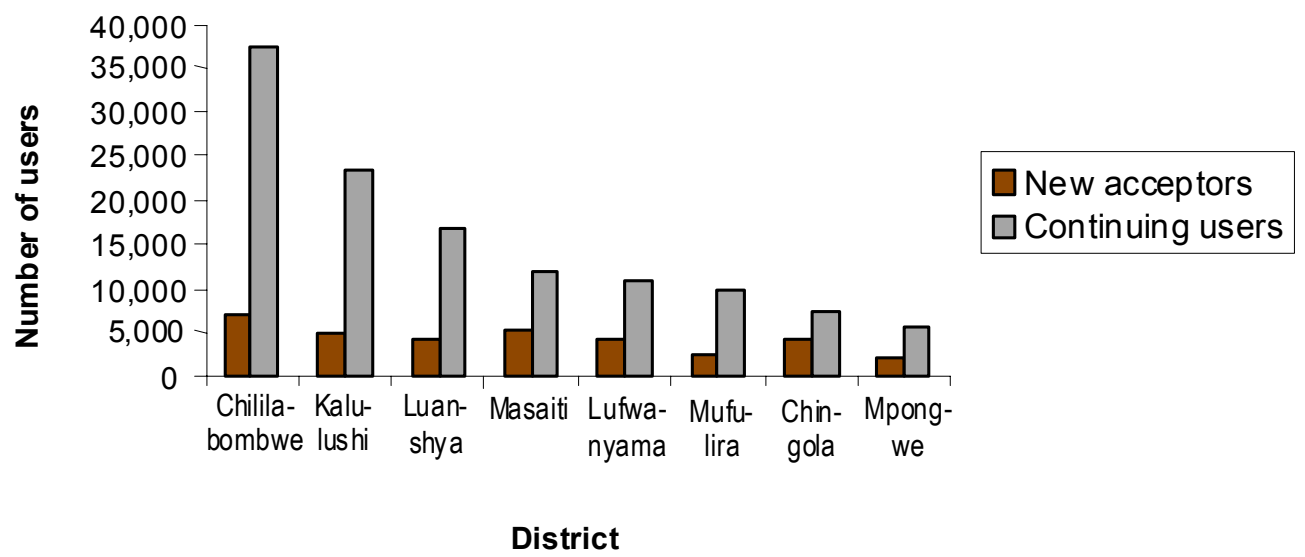

Material contributions, however, are not to be undervalued. One of the initiative's most notable accomplishments was increasing the method mix throughout the province, which also helped to increase uptake. At the outset of the project, only male condoms and oral contraceptives were routinely available in participating facilities. At the effort's conclusion, as shown in Table 3, five of the eight methods included in the minimal mix were offered in nearly all facilities. Of special note is the universal availability of injectables, which were reintroduced under the project. Other new methods such as female condoms and were made available in more than 80 percent of all facilities despite initial supply difficulties. Although IUD and BTL services were necessarily limited in scope because they require specialized personnel or facilities, access was dramatically increased through referrals and mobile IUD clinics. Although IUDs were offered on site at 41 percent of all clinics, the remaining 59 percent actively referred for the service, ensuring 100 percent coverage. BTL access was nearly as widespread, with a total coverage rate of 97 percent (factoring in on site and referral services).

Table 3: Contraceptive methods offered by participating service delivery points

\begin{tabular}{|l|r|r|r|r|r|r|r|r|}
\hline Facilities & Pill & $\begin{array}{r}\text { Inject- } \\
\text { ables }\end{array}$ & $\begin{array}{r}\text { Male } \\
\text { condom }\end{array}$ & $\begin{array}{r}\text { Female } \\
\text { condom }\end{array}$ & EC & SDM & IUD & BTL \\
\hline $\begin{array}{l}\text { Number offering } \\
\text { method/ referral }\end{array}$ & 37 & 37 & 36 & 31 & 31 & 19 & $15^{\star} / 22$ & $7 / 29$ \\
\hline $\begin{array}{l}\text { Percent offering } \\
\text { method/ referral }\end{array}$ & 100 & 100 & 97 & 84 & 84 & 51 & $41^{*} / 59$ & $19 / 78$ \\
\hline
\end{tabular}

*Includes mobile clinics. 
As indicated in Figure 5, the popularity of the methods mirrored their availability, suggesting that access has an impact on use. Those methods that could be obtained at nearly all SDPs (pills, injectables, and MCs), also had the highest rates of use. Those that were slightly less accessible, such as female condoms and SDM, were also less likely to be used. Despite active referrals and even mobile clinics, IUDs and BTL remained among the least popular of the methods. Only 148 IUDs were inserted during the life of the project, and 59 BTLs were performed. The challenges identified during the course of implementation (see page 9) likely continued to plague the program, undermining even the most innovative attempts to broaden access to these provider-dependent methods. Emergency contraception is the sole exception to this pattern; despite its widespread availability, its use remained the lowest of all methods, with only 55 doses administered during the life of the project. This finding partly reflects EC's status as a backup method, reserved for relatively infrequent emergencies, as well as the late procurement and repackaging of stocks for project use.

\section{Figure 5: Most popular contraceptive methods for new and continuing users}

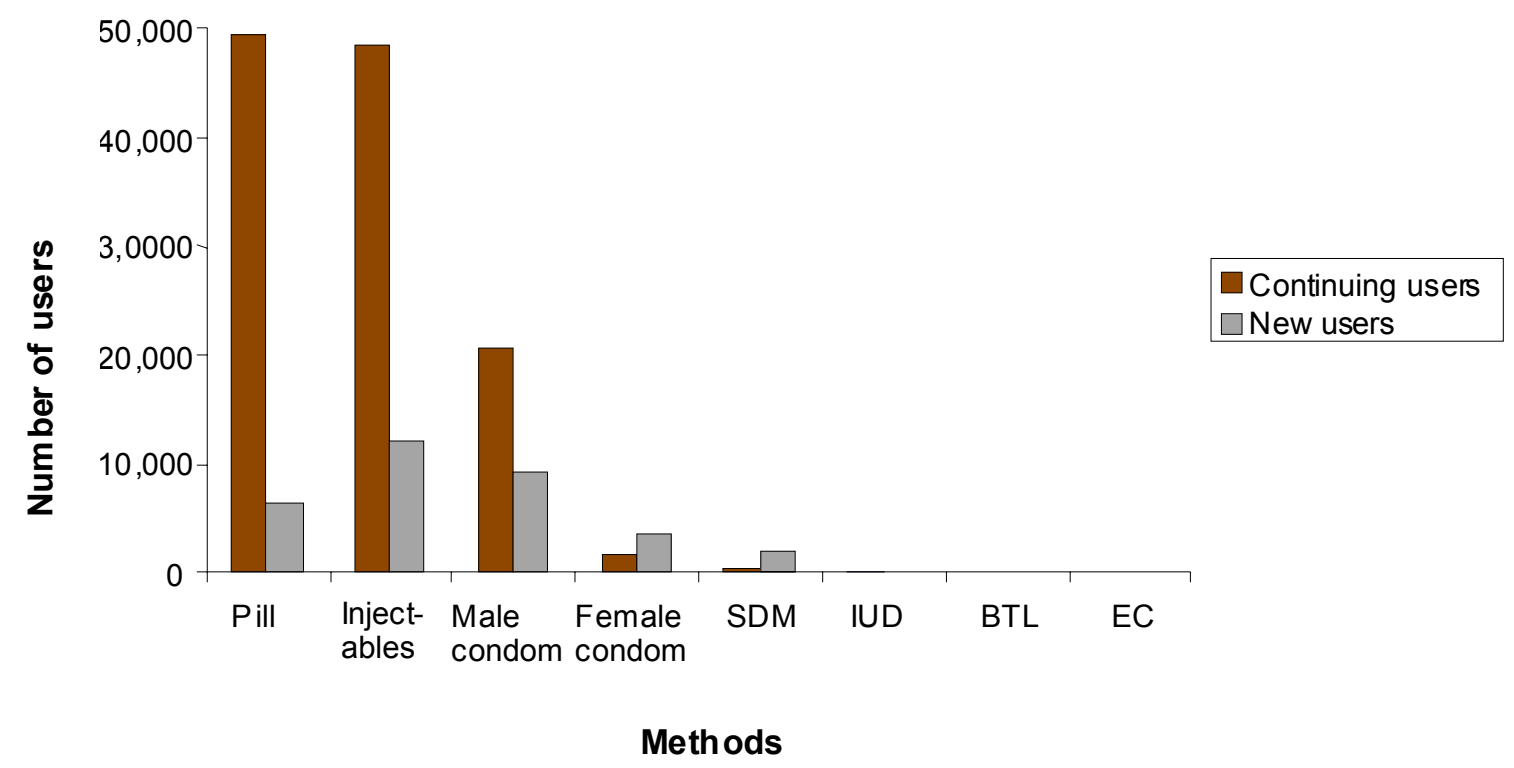

Among the three methods with near-universal availability important differences were seen in uptake patterns. New users were more likely to opt for injectables and male condoms than for oral contraceptive pills, whereas continuing users showed a slight preference for pills. This is a reflection, perhaps, of the large number of women who were using oral contraceptives before the program launched. These differences clearly indicate the benefit of offering a broad range of methods in order to respond to the diverse needs of clients.

The findings for the SDM provide a cautionary tale on the importance of commodity security. At the initiative's outset, SDM emerged as a runaway success. Popular with faith-based facilities and clients alike, requests for the method came even from clinics outside the study area. Service delivery data, as reflected in Figure 6, demonstrated that the number of new SDM users increased dramatically during the initiative's first 
months. An early evaluation by the Georgetown Institute for Reproductive Health identified a set of factors contributing to its success, including: intensive investments in provider training, community sensitization, supportive supervision, and preference for "natural" family planning methods. ${ }^{11}$

Figure 6: Number of new users of the standard days method, by project quarter

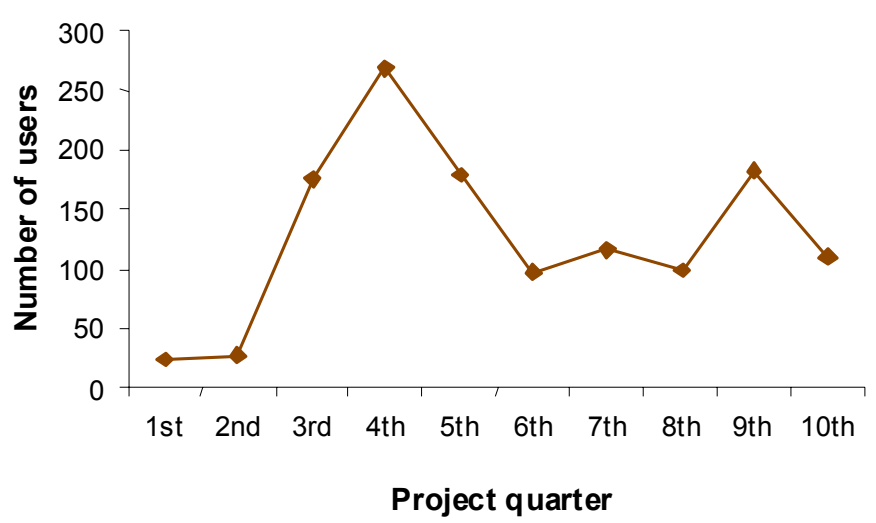

By the end of the fourth quarter, however, facilities began experiencing shortages of CycleBeads, ${ }^{\circledR}$ the tool that allows clients to anticipate accurately the fertile and "safe" days in their cycle. Stockouts in previously well-performing regions led to a decline in uptake that continued until the eighth quarter, when a small procurement of stocks reinvigorated the program for a short time. Ultimately, the gains of the first quarters were never recaptured because provider's enthusiasm for the method was undermined by concerns over sustainability.

\section{Dual Protection}

Despite intensive efforts to promote and record dual protection (DP), the initiative found this approach to be fraught with difficulties. Although the program registered a promising start for DP, interest in this approach decreased over time. Figure 7 shows that just as single-method use portrayed in Figure 2 was taking off, dual-method use was declining. While the number of new and continuing single-method users exceeded 150,000 by the end of the project, only 4,357 women opted for DP.

11 Anastasti Erin. September 2003. Trip report to monitor and assess progress of standard days method integration into the Population Council/Zambia Central Board of Health's "From Pilot Interventions to Regional Programs: Expanding Contraceptive Choice and Improving Quality of Care in the Copperbelt" project in eight districts of the Copperbelt Province, Zambia. Report prepared for the Institute of Reproductive Health, Georgetown University, Washington, DC. 
Figure 7: Number of users of dual protection, by project quarter

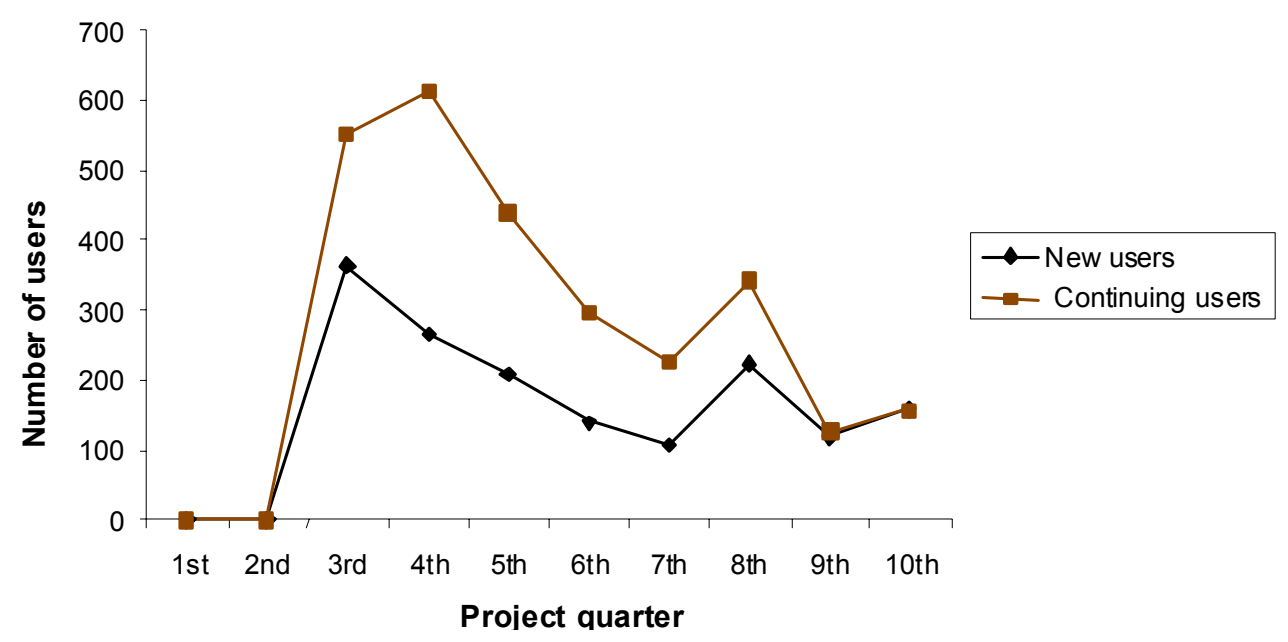

To better understand the relative unpopularity of this choice, the initiative conducted a study focused on the dynamics of DP. Undertaken at the conclusion of the intervention, this study included a review of all service statistics, a survey of 83 providers at all participating facilities, in-depth interviews with users and nonusers of DP and workshops with district supervisors to review procedures for promoting DP. 12

As with single-method use, use of DP varied across districts. Four districts stood out as the best performers; more than 80 percent of all new and continuing DP users obtained methods from providers in Masaiti, Chililabombwe, Kalulushi, and Chingola (see Figure 8). This differential is believed to reflect the skills and interests of providers, which does not closely resemble the pattern of provision seen in Figure 4. Only Chililabombwe and Kalulushi excelled in terms of both single- and dual-method use, indicating that success with single-method use does not necessarily translate into success with dual protection. This finding, as highlighted below, can be attributed to resistance on the part of clients and confusion among providers.

12 Rumbold, T. et al. 2006. Dual Protection: Single Figures in Zambia's Copperbelt. Nairobi: Population Council. Unpublished report. 
Figure 8: Number of users of dual protection, by district

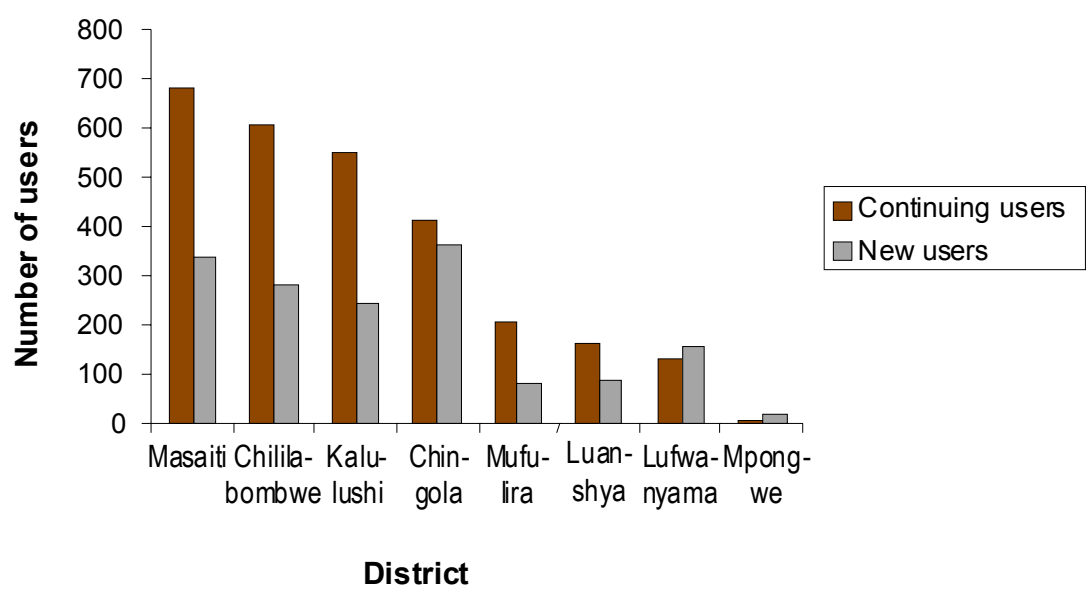

In the PRP initiative, dual protection referred exclusively to dual-method use, in which a condom (male or female) was used to prevent HIV transmission together with another method to prevent pregnancy. Service statistics indicated that users were most likely to combine condoms with pills, injectables, SDM and in the case of condom failure, EC. As outlined in Figure 9, oral contraceptives and injectables were by far the most popular methods among DP users, replicating the patterns of single-method use shown in Figure 5. This finding suggests that the contraceptive preferences of these populations are much the same, with concern for disease prevention serving as the primary distinguishing factor between the groups. The popularity of reflects the success of provider training and client counseling, which emphasize condom use during fertile periods.

Figure 9: Methods most frequently combined with condoms for dual protection

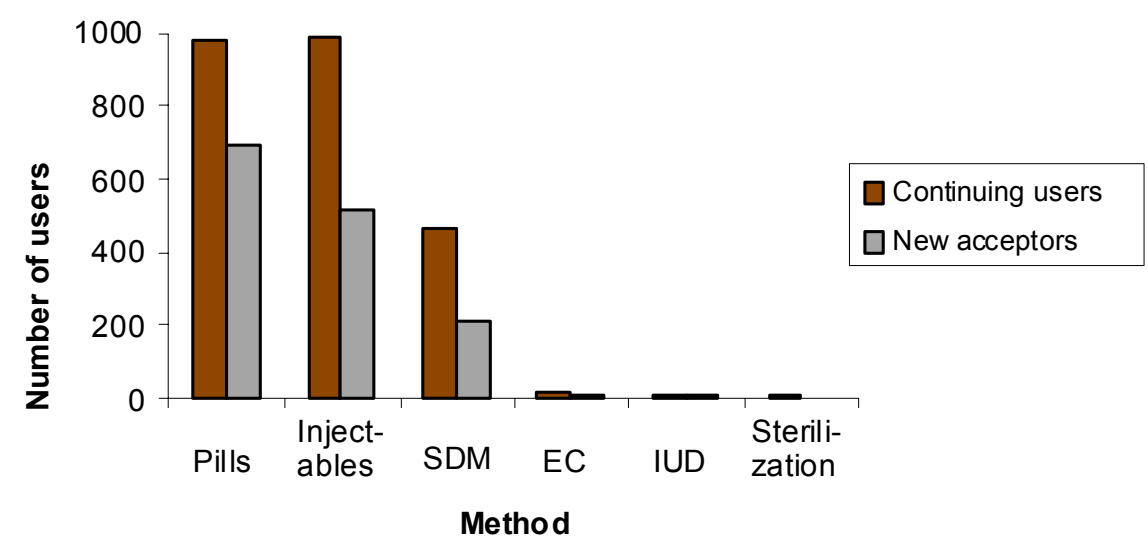

Data also demonstrated that DP was most commonly used among couples older than 30 in newly formed or noncohabitating relationships. According to respondents, condom use could most easily be negotiated in such relationships, whereas in longterm unions it tended to signify mistrust or suspicion. Figure 10 highlights the age disparity among DP users. 
Figure 10: Users of dual protection, by age and project quarter

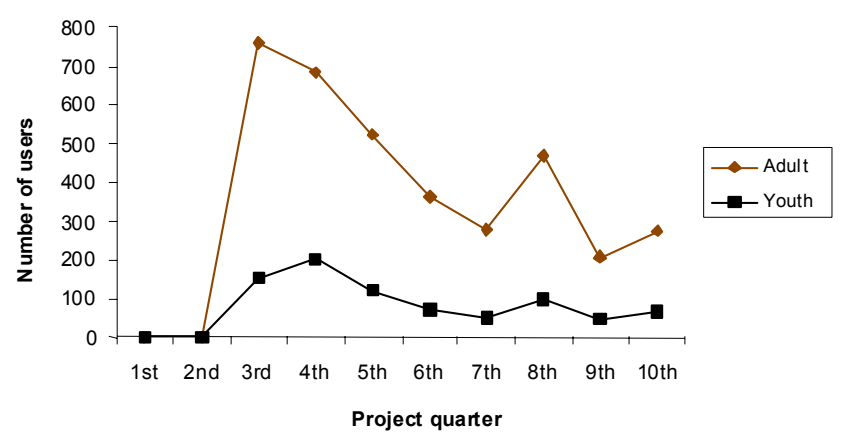

To help explain the limited popularity of dual protection, researchers identified a range of social and cultural disincentives that inhibit use.

- The concept of dual-method use is widely seen as impractical or unnecessary. Many respondents did not grasp the logic of dual-method use, citing family planning as their primary concern, followed only distantly by HIV transmission. Without a compelling reason to use two methods, the logistics of procuring and using both during every incidence of intercourse seemed daunting and irrelevant.

- Women are most likely to see the need for DP, but they also have limited negotiating power. Many women identified with the need to protect themselves from their partner's suspected infidelity, but believed that suggesting condom use would create intolerable disharmony in the relationship. Gender and power disparities tended to undermine women's negotiating ability.

The study also looked at the institutional and programmatic issues that inhibited DP uptake.

- Confusion existed among providers concerning the concept. Although most providers (96 percent) understood DP use as a combination of two methods, they primarily saw it as a means for inhibiting HIV transmission, overlooking its contraceptive and STI-related benefits. This misperception had negative implications for the identification and counseling of eligible clients. More intensive training and supervision were identified as strategies for overcoming such confusion.

- Despite the initiative's concerted efforts to capture dual-method use in clinics, providers believed that not all use was reflected in service statistics. The wall chart specifically designed to collect this information was found to be awkward, and its regular completion was inhibited by time constraints. Additionally, the burgeoning condom market outside of clinics made it impossible to fully gauge condom purchases by family planning users. Nonetheless, both providers and community respondents agreed that DP was not a commonly used strategy.

These results demonstrate that DP can be a valuable protection strategy for certain contraceptive method users, although more intensive community awareness and training of providers must be conducted in order to make it a viable, intuitive option. 


\section{A Model for Scaling Up}

In addition to testing the effectiveness of interventions to expand contraceptive choice, the project worked to develop a model for scaling up those interventions. This framework, represented in Figure 1 (page 3), informed the nature and structure of the intervention as a whole. It provided planners with a conceptual model upon which to base decisions about the content, process, and organization of the PRP initiative. The initiative's success in expanding contraceptive choice throughout the Copperbelt highlights the usefulness of such a framework in moving programs to scale.

The framework also proved to be effective in minimizing the conflicts inherent in the process of project planning. The project-design team found that the interrelationships between each point of the framework offered practical entry points for relieving many of these tensions, thereby minimizing their impact at the outset. The inverse relationship between quality and quantity (or scale), for example, is one linkage the design team found that could be addressed through interventions relating to content and process. Similarly, the dimensions of content and organization provided ample opportunities to maximize efficiencies and thereby lower the costs of moving to scale. Finally, the relationship between process and organization highlighted the tradeoffs between broadening geographical coverage and maintaining responsiveness to local needs and circumstances. The conceptual framework rendered these conflicts more manageable and provided the team with a practical tool for making sense of the ambiguities associated with moving from pilots to regional programs.

\section{NeXt Steps: Regional to NATIONAL Programs}

The success of the PRP initiative has been widely recognized and applauded. The $\mathrm{MOH} / \mathrm{CBOH}$ of Zambia has formally identified it as a best practice in reproductive health and has selected it as the model for scaling up reproductive health services over the coming decade. The Ministry has requested assistance from the Population Council and WHO to develop funding proposals that will make such an expansion possible.

Furthermore, the sustainability of PRP will not depend on the province alone or on the enthusiasm of the $\mathrm{MOH}$. The national health system has recently undergone structural reforms, including the dissolution of the $\mathrm{CBOH}$, and the Copperbelt is undergoing social and economic change as reopened mines breathe life into formerly depressed areas and once-active areas slide into decline. The end of funding to PRP from the United States Agency for International Development (USAID) in August 2005 is testing the initiative's sustainability, the depth of its local ownership, and the degree of publicsector confidence in its ability to scale up reproductive health services. Whether the participating districts and provinces can sustain their commitment to the activities of PRP remains to be seen. Little doubt exists, however, that the experience and the conceptual and practical lessons derived from the scaling up process will play an important role in future efforts to expand and improve the quality of reproductive health services in Zambia. 


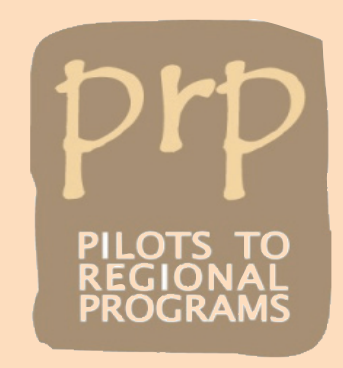

Zambia Ministry of Health

P.O. Box 30205

Lusaka, Zambia

Tel: +260 I 253040
Coperbelt Provincial Health Office P.O. Box 70032

Ndola, Zambia

Tel: $+260268 \mid 274$
Population Council, Nairobi

P.O. Box 17643

00500 Nairobi, Kenya

Tel: +254 20 27|3480-3

Email: info@pcnairobi.org
Population Council, Zambia Private Bag RW319X

Lusaka, Zambia

Tel: +260 । 255035

Email: pcouncil@zamnet.zm 